\title{
What is digital about dentistry?
}

\author{
Stephen Hancocks OBE \\ Editor-in-Chief
}

The BDJ Upfront section includes editorials, letters, news, book reviews and interviews. Please direct your correspondence to the News Editor,

Kate Quinlan at BDJNews@nature.com. Press releases or articles may be edited, and should include a colour photograph if possible.

$\mathrm{H}$ asn’t dentistry always been digital? OK, I'm teasing. Dentistry has always been digital in the sense that it requires human hands and fingers to skilfully treat patients. What has happened in recent years is that the word 'digital' has been used to define the technical difference between analogue (old) and digital (new) frequencies - digitally processed signals, to be precise.

However, in being used in this way the word has been ceased upon and hijacked by publicists such as marketers and advertisers as shorthand to convey a series of ideas or aspirations; modern, electronic, fast, twentyfirst century, in fact to mean whatever we as consumers want to interpret it as. So, as far as digital dentistry is concerned it can be interpreted to mean whatever each of us as dental professionals wish it to be. What does it mean to you?

I can date back my own understanding of the application of the term to the 1990s with the advent of computer aided design and computer aided manufacture (CAD/CAM) technology. At that time it seemed truly revolutionary. To be able to scan a prepared tooth, have that information communicated to a computer and then see a restoration perfectly milled from a solid block of material was astonishing; science fiction. Nowadays of course it is taken very much for granted but that is the nature of most advances. The application of 'digital' to so many items, pieces of equipment and services has somewhat devalued its meaning so here, in considering the consequences of so many changes, I am using it to delineate primarily electronic developments that affect our daily professional working lives.

The list is very long and, for me, if it began with CAD/CAM technology it now embraces radiography, intra-oral cameras and scanners, orthodontic alignment, practice management software, appointment systems and social media to mention only a few. Your own list will be different and personal depending on your scope of practice, probably your age, the year in which you qualified and your own take on whether technology is of amazing value or just a modern curse.

However, the world plunges onwards, irrespective of our individual lists and attitudes and it is the influence that these changes have on the way in which we practise dentistry which we need to consider very carefully. If we do not, we risk not being able to offer our patients the very best and most-informed care and falling behind in our ability to create an efficient and developing business. In the same way in which CAD/CAM may now be seen as somewhat passé in comparison say to $3 \mathrm{D}$ printing (although the latter process uses makes easier or quicker or more efficient. Digital radiography, for example, exposes the patient to a far lower dose of radiation. That is a huge benefit and one which can of course be conveyed to them. It is more likely that the greater value they perceive is that they don't have to make another appointment to come back to the practice to get the results. Instant access, immediate diagnostic information, better clinical care... and more time for them to do something other than return to your surgery.

It is these aspects of digital evolution that I believe we are in danger of overlooking. Not simply the possible economic risk of deciding whether to invest in a new piece of kit but missing the opportunity to reflect on the way in which the integration of these

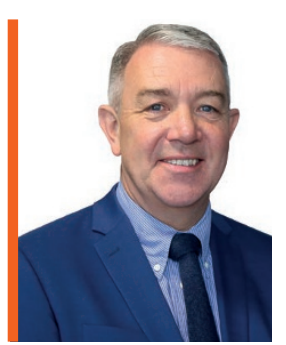

\section{'The value is often different from the task that the technology makes easier...'}

similar technology but is additive rather than reductive) our ability to adapt and modify our behaviour means that we can easily become complacent. We now look twice at a phone box in the street because it is such a rarity - so old fashioned, imagine having to go to a fixed booth to make a phone call. How did the world revolve without mobile phones? (Actually mobile telephones; not 'phones but who adds the apostrophe anymore? - so old fashioned). You get the point.

But the risk we run is being so enraptured by the genius of the creation of a particular type of technology that we lose sense of its value. What is the application and how can it help us in dentistry? The value is often different from the task that the technology various technologies can enhance our service and our own lives. What seems today as having no direct effect, such as perhaps the phasing out of petrol and diesel cars and the advent of driverless cars will in no time at all lead to a revolution in patient behaviour, economic impact and geopolitical balances of power - will there be such a thing as a domiciliary patient? How will lab work be delivered? Will we need to buy oil from the Middle East anymore? I do not know the answers to these questions anymore than you do but what I suggest is that it would be productive to spend more time pondering some of them rather than holding up a digit to see which way the wind is blowing.

DOI: 10.1038/sj.bdj.2017.732 